\title{
Knowledge, perception and determinants of utilization of pharmacovigilance services among healthcare practitioners in Abuja.
}

\author{
Akor, A.A. ${ }^{1}$, Ajiga, E.A. ${ }^{2}$, Akor, B.O. ${ }^{3}$
}

\begin{abstract}
Objective: To determine knowledge, perception, practice and determinants of utilization of pharmacovigilance services among healthcare practitioners (HCP).
\end{abstract}

Methods: This was a cross sectional study of HCP. A self-administered structured questionnaire was developed and pretested before administration. The participants were selected randomly using a sampling interval of four. Three hundred and forty questionnaires were administered. Data obtained were analyzed using SPSS version 20.

Results: The response rate was $89 \%$, of which $42 \%$ were males. Majority of the respondents had good knowledge of pharmacovigilance (PV), however only about $11.8 \%$ have reported Adverse Drug Reactions (ADR), 26\% have ever been trained on PV, 27\% knew of the ADR reporting tool, the "yellow form". The major reason for underreporting of PV was ignorance on the part of the practitioners.

Conclusion: The practice of PV among HCP is low, possible reasons include low training and poor knowledge of the ADR reporting tool. We recommend regular training of $\mathrm{HCP}$ to improve PV services.

Keywords: Pharmacovigilance, knowledge, Healthcare practitioners (HCP), Adverse Drug Reaction (ADR) reporting, determinants of utilization.

*Correspondence author

Dr Akor, A. A

http://orcid.org/0000-0002-6557-5392

Email:alexander.agada@uniabuja.edu.ng

Department of internal medicine, University of Abuja

Department of Pharmaceutical services, University of Abuja Teaching hospital, Gwagwalada, Abuja.

Department of Family Medicine, University of Abuja Teaching Hospital, Gwagwalada, Abuja 


\title{
Connaissance, perception et déterminants de l'utilisation des services de pharmacovigilance chez les professionnels de la santé à Abuja.
}

\author{
Akor, A.A. ${ }^{1}$, Ajiga, E.A. ${ }^{2}$, Akor, B.O.
}

\section{Resume}

Objectif: Déterminer les connaissances, la perception, la pratique et les déterminants de l'utilisation des services de pharmacovigilance chez les professionnels de la santé.

Méthodes: Il s'agissait d'une étude transversale de HCP. Un questionnaire structuré auto-administré a été élaboré et prétesté avant administration. Les participants ont été choisis au hasard en utilisant un intervalle d'échantillonnage de quatre. Trois cent quarante questionnaires ont été administrés. Les données obtenues ont été analysées à l'aide de la version SPSS 20.

Résultats: Le taux de réponse était de $89 \%$, dont $42 \%$ d'hommes. La majorité des personnes interrogées connaissaient bien la pharmacovigilance (PV), mais seulement $11,8 \%$ environ ont signalé des effets indésirables des médicaments (ADR), 26\% avaient déjà été formés au PV, 27\% connaissaient l'outil de notification ADR, la "forme jaune". . La principale raison de la sous-déclaration de PV était l'ignorance de la part des praticiens.

Conclusion: La pratique de la PV chez les professionnels de la santé est faible, notamment en raison de la faible formation et de la méconnaissance de l'outil de notification des réactions indésirables aux médicaments. Nous recommandons une formation régulière du HCP pour améliorer les services PV.

Mots-clés: pharmacovigilance, connaissances, praticiens de la santé (HCP), notification des effets indésirables des médicaments (ADR), déterminants de l'utilisation.

*Correspondence author

Dr Akor, A. A

http://orcid.org/0000-0002-6557-5392

Email:alexander.agada@uniabuja.edu.ng

Department of internal medicine, University of Abuja

Department of Pharmaceutical services, University of Abuja Teaching hospital, Gwagwalada, Abuja.

Department of Family Medicine, University of Abuja Teaching Hospital, Gwagwalada, Abuja 


\section{INTRODUCTION}

Pharmacovigilance (PV) is defined by the World Health Organization (WHO) as the science and activities relating to detection, assessment, understanding and prevention of adverse effects or other drug related problem (1). The complete safety profile of a drug is hardly ever obtained through clinical investigations or trials alone. On release of a drug for public use, there may be concomitant use of the drug with other drugs, foods and substances. Thus, pharmacovigilance has been put in place to act as a "post clinical investigation" tool to detect and prevent potentially rare and serious ADR that may arise from interaction of the drug with other substances or diseases. PV could also be useful in identifying novel uses for a particular drug different from its original indication (2).

The World Health Organization describes pharmacovigilance "as an obligatory investment in the future public health of its territory". Adverse drug reactions affect all age groups (3). Several studies have linked adverse drug reaction as a cause of prolonged hospital stay which may worsen patient's condition or lead to mortality $(4,5)$. Reporting adverse drug reactions spontaneously has been highlighted as the major predictor of success of pharmacovigilance (6). However this has not been the story of pharmacovigilance worldwide as several studies carried out have named underreporting as the main hindrance to the success of PV. $(7,8,9)$ even though as at 2002 , the WHO monitoring centre for International Drug surveillance had received well over three trillion case reports from member states National Pharmacovigilance Centers (10).

Pharmacovigilance Centre in Nigeria is National Agency for Food and Drug Administration and Control (NAFDAC), is charged with responsibility of coordinating all pharmacovigilance activities within the country whilst relaying information on pharmacovigilance to $\mathrm{WHO}$ as appropriate. As at 2010, only about 5000 Individual Case Safety Reports of ADRs had been received by the NPC, a figure that fell short of the expected estimate given by WHO which is 28000 reports/ year.

Healthcare providers are an integral part of documentation of a total safety profile of a drug. For a Pharmacovigilance program to be successful there has to be constant collaboration and communication between all healthcare practitioners and the National Pharmacovigilance Center (NPC) (11). In Nigeria, underreporting of ADR events by HCPs have been highlighted by several studies as a major hindrance to the success of Pharmacovigilance. $(12,13,14,15)$.

The present study therefore aims to determine knowledge, perception, practice and determinants of utilization of pharmacovigilance services among healthcare practitioners in a teaching hospital in Nigeria's capital; Abuja.

\section{MATERIALS AND METHODS}

The study location was University of Abuja Teaching Hospital (UATH) Gwagwalada. The hospital is a tertiary health facility with 350 bed spaces, located in one of the Federal Capital Territory (FCT) municipal council, Gwagwalada. This was a cross sectional questionnaire based study. Ethical approval was obtained from the hospital ethics and research committee of the hospital before commencement of the study.

The study population was approximately 1300 healthcare givers including doctors, nurses, pharmacists, physiotherapists, medical laboratory scientists, radiographers, ophthalmologists, and dental technologists. Sample size was three hundred and six (306). Sample size was determined using Taro Yamane formula for Sample Size determination. (16). Sample size calculation.

Taro Yamane: $0=0] /\left(\left(1+2(\text { 回 })^{2}\right)\right)$

$\mathrm{n}$ :signifies the sample size $=$ ?

$\mathrm{N}$ : signifies the population under study $=1300$

e: signifies the margin error $=0.05$

$\mathrm{n}=1300 /\left(1+1300(0.05)^{2}\right)$

$\mathrm{n}=1300 /(1+1300(0.0025)$

$\mathrm{n}=1300 /(4.25)$

$\mathrm{n}=306$

A pretested questionnaire adopted from Lokesh et al., (17) was used for the survey and modified to suit the study setting. A pilot study was carried out before the main survey to further modify the any unforeseen error. The questionnaire was divided into two sections. Section A captured demographic information while in section $\mathrm{B}$, questions 1-8 were based on knowledge of pharmacovigilance, questions 9-12 focused on perception about pharmacovigilance, questions 13- 20 assessed practice of pharmacovigilance and questions 21 to 23 focused on determinants of utilization.

Participants were selected by systematic random sampling method, using a sampling interval of four.

Data from the retrieved questionnaires were coded, entered and analyzed using Statistical Package for Social Sciences (SPSS) 
version 20. Five questions were selected to assess the knowledge level of the various domains of $\mathrm{PV}$, participants who answered three questions correctly out of the five domain questions were grouped as having good knowledge of PV, while those who answered less than three questions correctly were grouped as having poor knowledge. Logistics regression was used to determine any relationship/correlation between the overall knowledge score and certain other variables such as having additional qualification, having previous training on PV prior to the current study and having read an article on PV prior to the current study.

\section{RESULTS}

Three hundred and forty questionnaires were distributed. A total of 304 were recovered giving a response rate of $89 \%$, of which forty two percent $(42 \%)$ were males and fifty eight percent $(58 \%)$ were females. Among the respondents, the doctors were the highest respondents $101(33.2$ $\%)$ while the physiotherapists were the least number of respondents $(9.9 \%, 30)$. See Table 1 .

Majority of the respondents had good knowledge of pharmacovigilance (73\%). For the five domain questions chosen to assess $\mathrm{PV}$, $72.7 \%$ and $74.3 \%$ of the participants knew the definition and scope of PV respectively, and $80.9 \%$ of the participants knew that all health care practitioners were responsible for the reporting of ADR. Only about 27\% knew the "yellow" form as the ADR reporting tool in Nigeria and 34.5\% knew the National Pharmacovigilance Center (NPC) in Nigeria. See Table 2b.

The study showed that respondents have a very good attitude toward pharmacovigilance, 98.4\%(299) of the participants thought ADR reporting is necessary, $95.7 \%$ (291) suggest that PV should be taught in details to HCP, while $89.5 \%$ was of the opinion that ADR reporting is a professional obligation.

On the questions assessing practice of PV among HCP, 66\% have read articles on prevention of ADR. Sixty four percent (64\%) have experienced ADR during their professional practice and about 58\% have not seen an ADR form. Only $26 \%$ have been trained to report ADR and a meager $11.8 \%$ have reported ADR to the PV center. About 19\% are aware of the PV center in the institution.

When respondents were asked about their preferred methods of reporting ADR, approximately $37 \%$ prefer reporting through mail or website information while $30.7 \%$ chose to report directly (direct contact) to the center,
$27.3 \%$ prefer reporting through telephone, $2.5 \%$ would rather send reports through the post office. The current study identified several reasons for underreporting; most prominent among the reasons was that respondents did not know where/how to report ADR 89, (30\%), while about $3 \%$ of the respondents believe "a single unreported event would not affect the ADR database". See Table 3.

Respondents also highlighted other possible reasons that affect underreporting, which include been not aware of reporting procedure, non-availability of reporting units on the ward, no functioning PV program in the institution, too many drugs to detect which caused ADR and lack of advocacy.

Table 4 shows results of logistic regression for possible predictors of good knowledge of Pharmacovigilance. The dependent variable was "knowledge of PV of the respondents" while the independent variables include, "having additional qualification", "trained on how to report ADR", "having read an article on PV". Being "Trained on how to report ADR" is the most likely factor to increase the knowledge of PV by twice compared to those who did not receive any further training.

\section{DISCUSSION}

The major aim of any PV program is to prevent ADRs. The response rate obtained from this was eighty-nine percent (89\%), this is similar to other like studies. (18). This could infer that, if the ADR reporting forms are readily available, response rate in filling them would also be high. Five different HCP groups participated in the study, unlike several other studies which were limited in the category of $\operatorname{HCP}(19,20,21)$. This was done to assess other HCP who are often not included in studies such as this.

In this study, awareness of the designated form (Yellow form) was low (27\%), compared to a similar study conducted by Okechukwu et al., (13), which reported knowledge level of yellow form at about $50 \%$. This could be attributed to the deficiency in training, as only about $26 \%$ of the respondents were trained on ADR reporting. The poor awareness of the yellow form could also be attributed to low level of training on PV in Nigeria especially during undergraduate studies as reported by Showande and Fakeye, (22).

Underreporting of ADR has been highlighted by several studies around the world as a factor limiting the success of PV $(12,19,23)$. The current study is not an exception considering that only about $10 \%$ of the respondents ever 
reported occurrence of ADR. This could be attributed to the low number of HCP in the study who had been trained on ADR reporting (26\%), a low value of $22 \%$ has also been reported by another study(7).

Despite the fairly high scores seen in respondents who have experienced ADR and have read articles on ADR prevention (above $60 \%$ ), reporting of ADR among HCP was quite poor, as seen in similar studies (8).

The determinants of utilization were assessed in the present study, of which "didn't know how/where to report" was the most recurrent reason for underutilization. Other reasons given for underutilization of PV services include, "difficulty of the HCP to determine whether a particular drug caused the ADR" (19.7\%), "reporting ADR will yield no response from authorities", "lack of time to report ADR" and "single unreported event may not affect ADR database". Also among the determinants, provision of financial incentives for HCPs who report ADR was surprisingly a determinant of utilization. Corroborating the studies done by of Shaibu and Mohammad $(9,24)$. From our study, we observed that HCP are were willing and appear interested in participating in $\mathrm{PV}$, as almost all respondents had a positive attitude towards PV.

The logistics regression done showed that this study also identified previous training on $\mathrm{PV}$ as a major predictor of PV $(\mathrm{p}=0.04)$. Having read an article or having additional qualification did not contribute to the possible knowledge of PV. However, being trained on PV showed that. This agreed with other studies. $(25,26)$ in which training was shown to have a mild impact on the overall knowledge and practice of pharmacovigilance among health care providers. (25)

The strength of this study lies in its inclusion of more groups of healthcare practitioners. However our findings should be interpreted with caution as this study is an institutional based study, as varying results could be obtained if the same study is carried out in the community or other health care settings such as primary and secondary healthcare facilities.

\section{CONCLUSION}

In conclusion, the practice of PV among $\mathrm{HCP}$ is low, possible reasons include low training and poor knowledge of the ADR reporting tool. Knowing where and how to report was the most recurrent determinant of underreporting. Respondents have very good attitude toward PV.
The WHO describes a national PV system "as an obligatory investment in the future public health of the territory." (27). We recommend there should be improved awareness, through regular training and retraining at undergraduate and professional level respectively.

Conflicts of Interest: The authors declare no conflicts of interest.

\section{REFERENCES}

1. World Health Organization. Essentials medicines and health products: pharmacovigilance [Internet]. Geneva: World Health Organization; 2004 Oct [cited 2018 Jul 9]. Available from: http://www.who.int/medicines/areas/quality_saf ety/safety_efficacy/pharmvigi/en/

2. Naik P. The Future of Pharmacovigilance. J Pharmacovigil. 2015; 3: 159.

3. Oshikoya KA. Adverse drug reaction in children: types, incidence and risk factors. Nig J Paediatr. 2006;33:29-35.

4. Kongkaew C, Noyce PR, Ashcroft DM. Hospital admissions associated with adverse drug reactions: A systematic review of prospective observational studies. Ann Pharmacother. 2008;42(7):1017-25.

5. Patel KJ, Kedia MS, Bajpai D, Mehta SS, Kshirsagar NA, Googtay NJ. Evaluation of the prevalence and economic burden of adverse drug reactions presenting to the Medical emergency department of tertiary referral centre: a prospective study. Clin Pharmacol. 2007;7(1):15

6. Gupta SK. Text book of pharmacovigilance: Current Methods of Pharmacovigilance. New Delhi: Jaypee brothers Medical Publisher (P) Ltd; 2011.p. 28-38.

7. Subramaniyan G, Gunaseelan V, Kishtapati CR, Subrahmanyam DK, Chandrasekaran A. A survey on knowledge, attitude and practice of pharmacovigilance towards adverse drug reactions reporting among Doctors and Nurses in a Tertiary Care Hospital in South India. J Young Pharm. 2016;8(4):471-476

8. Fatemah A, Sherifah A, Eman A, Tania B, Jacinthe L. Knowledge, attitude and practices of pharmacovigilance and adverse drug reaction reporting among pharmacists working in secondary and tertiary governmental hospitals in Kuwait. Saudi Pharm J. 2017;25(6):830-837.

9. Shaibu OB, Mohammad TU. Knowledge and attitude of physicians relating to reporting of adverse drug reactions in Sokoto, north western Nigeria. Ann. Afr. Med. 2011;10(1):13-18.

10. World Health Organization. The importance of pharmacovigilance: safety monitoring of medicinal products [Internet]. Geneva: World Health Organization; 2002 Jan [cited 2018 Jul 9]. A v a i 1 a b l e f $\mathrm{r}$ o m : http://apps.who.int/medicinedocs/en/d/Js4893e/. 
11. Gupta SK, Nayak RP, Shivaranjani R, Vidyarthi SK. A Questionnaire study on the knowledge, attitude and the practice of pharmacovigilance among the healthcare professionals in a teaching hospital in South India. Perspect Clin Res. 2015;6(1):45-52.

12. Fadare J, Okezie O, Afolabi A. Knowledge, attitude and practice of adverse drug reaction reporting among healthcare workers in a tertiary center in Northern Nigeria. Trop J of Pharm Res. 2011;10(3):235-242.

13. Okechukwu R, Odinduka O, Ele G, Okonta J. Awareness, attitude, and practice of Pharmacovigilance among health care professionals in Nigeria. Int. J hosp. res. 2013; 2(3):99-108.

14. Adedeji A, Fehintola A, Ibraheem A. Attitude and practice of doctors toward adverse drug reactions (ADRs) reporting in a Nigerian tertiary health facility. Ann. Ib Postgrad Med. 2013;11(3):7780 .

15. Bello S, Umar M. Knowledge and attitude of physicians relating to reporting of adverse drug reactions in Sokoto, North-western Nigeria. Ann. Afr. Med. 2011 10(1): 13-8.

16. Singh A, Masuku M. Sampling techniques and determination of sample size in applied statistics research: an overview. Int. J. economics commerce manag. 2014;2(11):14-16.

17. Lokesh VR, Javeed SK, Mohanraj R, Padmanabha R. Assessment of knowledge, attitude and perception of pharmacovigilance and adverse drug reaction (ADR) reporting among the pharmacy students in south India. J Pharm. Biol. Sci. 2014;9(2):34-43.

18. Ebenebe UE, Ezeuko AY, Nnebu CC, Ugorji JO, Duru CB, Nwabueze AS. Adverse drug reaction reporting practices among health workers in Nnewi Nigeria. J int. res. Med.pharm. Sci. 2015;2(4):120-127.

19. Maniyan G. Gunaseelan V, Kishtapati C, Hmanyam D, Chandrasekaran A. A Survey on Knowledge, and Practice of Pharmacovigilance towards Adverse drug reactions reporting among Doctors and Nurses in a Tertiary Care Hospital in South India. J Young Pharm. 2016;8(4):471-476.

20. Su CJ, Su HY. Hospitals pharmacists' knowledge and opinions regarding adverse drug reaction reporting in Northern China. Pharmacoepidemiol Drug Saf. 2010;19(3): 217 22.

21. Hanafi S, Torkamandi H, Hayatshahi A, Gholami $\mathrm{K}$, Javadi M. Knowledge, attitude and practice of nurse regarding adverse drug reaction reporting. Iran J Nurs Midwifery Res. 2012;17(1): 21-25.

22. Showande S, Fakeye T. The concept of adverse drug reaction reporting: awareness among pharmacy students in a Nigerian university. Internet journal of medical update. 2013;24(8)30.

23. Khan S, Goyal C, Chandel N, Rafi M. Knowledge, attitudes, and practice of doctors to adverse drug reaction reporting in a teaching hospital in India: An observational study. J Nat Sc Biol Med.2013;4(1):191-6.

24. Bäckström M, Mjörndal T. A small economic inducement to stimulate increased reporting of adverse drug reactions - A way of dealing with an old problem? Eur J Clin Pharmacol. 2006;62:381-5.

25. Osakwe A, Ibrahim O, Adebowale JA, Abisola A, Iretiola F. Impact of training on Nigerian healthcare professional' knowledge and practice of pharmacovigilance. Int J Risk Saf Med 2013;25:219-227.

26. Mala K, Suresh B. Extent of under reporting of adverse drug reactions (ADRs) in India: Evaluation using logistics regression analysis (LRA) model. J Clin Trials. 2014; 4:1.

27. World Health Organization. The safety of medicines in public health programmes. Pharmacovigilance: an essential tool [Internet]. World Health Organization; 2006 April [cited 2018 Jul 9]. Available from: http://www.who.int/hiv/pub/pharmacovigilance/ safety/en/ 
Table1. General characteristics of study population

\begin{tabular}{lll}
\hline Variables & Frequency & Percentage \\
\hline Gender: & & \\
Male & 127 & 41.8 \\
Female & 177 & 58.2
\end{tabular}

\begin{tabular}{lll} 
Profession: & & \\
Doctors & 101 & 33.2 \\
Nurses & 88 & 28.9 \\
Pharmacists & 49 & 16.1 \\
Medical Laboratory & 36 & 11.8 \\
Scientists & 30 & 10.0 \\
Physiotherapists & & \\
Years of Practice & & \\
$1-4$ & 118 & 38.8 \\
$5-10$ & 86 & 28.3 \\
$11-20$ & 69 & 22.7 \\
$>20$ & 31 & 10.2 \\
& & \\
\hline
\end{tabular}

Table2a. Showing rating of knowledge of PV based on the various categories of HCP

\begin{tabular}{lll}
\hline Profession of respondents & Good knowledge (\%) & Poor knowledge (\%) \\
\hline Medical lab scientist & $18(50)$ & $18(50)$ \\
Nurse & $61(69.3)$ & $27(30.6)$ \\
Physiotherapist & $18(60)$ & $12(40)$ \\
Doctor & $82(81.1)$ & $19(18.8)$ \\
Pharmacist & $44(89.7)$ & $5(10.2)$ \\
Total & $223(73.3)$ & $81(26.6)$ \\
\hline
\end{tabular}

Table2b. Shows breakdown of various knowledge domain of PV and profession of respondent.

\begin{tabular}{llllll}
\hline Profession & $\begin{array}{l}\text { Definition } \\
\text { of PV (\%) }\end{array}$ & $\begin{array}{l}\text { Function } \\
\text { of PV } \mathbf{~} \%)\end{array}$ & $\begin{array}{l}\text { Scope of } \\
\text { PV (\%) }\end{array}$ & $\begin{array}{l}\text { ADR reporting } \\
\text { system (\%) }\end{array}$ & $\begin{array}{l}\text { HCP responsible } \\
\text { for ADR (\%) }\end{array}$ \\
\hline Doctors & 77 & 82.8 & 51 & 52.4 & 89.1 \\
Nurses & 74.7 & 75 & 48.8 & 13.7 & 88.4 \\
Pharmacists & 81.6 & 85.7 & 58.3 & 84.6 & 75 \\
Med. Lab. Sci. & 63.9 & 69.4 & 37.1 & 21.4 & 62.9 \\
Physiotherapists & 63.3 & 39.9 & 70 & 12.5 & 75.9 \\
\hline
\end{tabular}


Table 3. Factors discouraging ADR reporting by health care professionals

\begin{tabular}{|c|c|c|}
\hline Factors & Frequency & Percentage \\
\hline Didn't know how or where to report & 89 & $29.3 \%$ \\
\hline $\begin{array}{l}\text { Difficulty to decide whether drug } \\
\text { caused ADR }\end{array}$ & 60 & $19.7 \%$ \\
\hline $\begin{array}{l}\text { Reporting ADR will yield no } \\
\text { response from authorities }\end{array}$ & 51 & $16.8 \%$ \\
\hline Lack of time to report ADR & 32 & $10.5 \%$ \\
\hline No remuneration & 26 & $8.6 \%$ \\
\hline $\begin{array}{l}\text { Single un reported event may not } \\
\text { affect database }\end{array}$ & 9 & $3 \%$ \\
\hline
\end{tabular}

Note: Total frequency here varies from total number of retrieved questionnaires since some respondents chose not to tick a factor stated in the questionnaire. Their reason for underreporting was probably not captured in the list of factors provided. Some respondents however wrote their reason for underreporting.

Table 4: Results of logistics regression for possible predictors of knowledge of Pharmacovigilance

\begin{tabular}{|c|c|c|c|c|c|}
\hline Variable & B & S.E. & Wald & Sig. & $\operatorname{Exp}(B)$ \\
\hline $\begin{array}{l}\text { Having additional } \\
\text { qualification }\end{array}$ & 0.09 & 0.33 & 0.08 & 0.78 & 1.09 \\
\hline Having read an article & 0.01 & 0.14 & 0.01 & 0.93 & 1.01 \\
\hline $\begin{array}{l}\text { Trained on how to } \\
\text { report ADR }\end{array}$ & 0.65 & 0.31 & 4.46 & 0.04 & 1.92 \\
\hline
\end{tabular}

The dependent variable was "knowledge of PV of the respondents" while the independent variables include, "having additional qualification", "trained on how to report ADR", "having read an article on PV". The independent variable "Trained on how to report ADR" is the likely predictor in the model. 